\title{
Amaranthus retroflexus transgenic plants for phytoremediation
}

Vershinina Z.R., Khakimova L.R., Karimova L.R., Baimiev Al.Kh.

Institute of Biochemistry and Genetics - Subdivision of the Ufa Federal Research Centre of the Russian Academy of Sciences, Ufa, Russia

E-mail: zilyaver@mail.ru

Key message. Amaranthus retroflexus was transformed with the pph6 gene encoding the synthesis of a metal-binding peptide, which on average increased plant resistance to $\mathrm{Cd}$ and $\mathrm{Ni}$ by $15 \%$, the accumulation of heavy metals in plants increased by an average of $25 \%$.

Keywords: amaranth, phytochelatin, heavy metals, phytoremediation

Currently, the problem of soil pollution with heavy metals, which are toxic to all living organisms and cause severe diseases of animals and humans, is becoming increasingly urgent. One of the safest methods for cleaning contaminated areas is phytoremediation. The main task in soil phytoremediation is the search for hyperaccumulators plants that are capable of accumulating large concentrations of heavy metals. To increase the phytoremediation efficiency of plants, it is advisable to transform them with genes encoding the synthesis of metal-binding peptides. Amaranth is a widespread culture that has a high potential for use in phytoremediation, as it is characterized by rapid growth, resistance to adverse environmental conditions and the ability to accumulate high concentrations of heavy metals, in particular $\mathrm{Cd}$ and Ni. Previously, Amaranthus retroflexus plants (amaranth) were obtained, transforming with an artificially synthesized pph6 gene assembled from complementary blocks 5'ATGGAATGCGAATGTGAGTGCGAGTGCGAGTGCGAATGTGGCTAA3' and 5'TTAGAGACACTCTCGCACTCGCACTCGCAT3'. After stitching these blocks, the sequence was cloned into a vector for plant transformation pCambia 1301 under the control of the $35 \mathrm{~S}$ promoter of the cauliflower mosaic virus and and later used to obtain transgenic amaranth plants. For transformation, hypocotyls and epicotyls of amaranth seedlings were used on day 14 after emergence. To regenerate shoots, 2 $\mathrm{mg} / \mathrm{L}$ of BAP and $0.2 \mathrm{mg} / \mathrm{L}$ of NAA were added to the medium.

The pph6 gene product was found to increase plant resistance to heavy metals. On average, the dry biomass of transgenic plants increased by $18 \%$ when exposed to $100 \mu \mathrm{M} \mathrm{Cd}^{2+}$ and by $12 \%$ when exposed to $100 \mu \mathrm{M} \mathrm{Ni}^{2+}$ compared to control plants. The content of $\mathrm{Cd}^{2+}$ in transgenic plants was $33 \%$ higher than in the control; in the case of $\mathrm{Ni}^{2+}$, this indicator increased by $17 \%$. In general, $\mathrm{Ni}^{2+}$ was more toxic to amaranth. The experimental results led to the conclusion that it is advisable to use pph6 to increase the phytoremediation efficiency of plants.

This research was supported by the Russian Foundation for Basic Research (project nos. 34-00033 mol_a).

\section{Трансгенные растения Amaranthus retroflexus для фиторемедиации}

Вериинина 3.Р., Хакимова Л.Р., Садыкова Л.Р., Баймиев Ал.Х.

Институт биохимии и генетики - обособленное структурное подразделение Федерального государственного бюджетного научного учреждения Уфимского федерального исследовательского центра Российской академии наук, Уфа, Россия

Аннотация. Растения амаранта были трансформированы геном ррһб, кодирующим синтез металлсвязывающего пептида, что в среднем повышало устойчивость растений к Cd и Ni на $15 \%$, накопление тяжельх металлов в растениях увеличивалось в среднем на $25 \%$.

Ключевые слова: амарант, фитохелатин, тяжелье металль, фиторемедиация

В настоящее время все более актуальной становится проблема загрязнения почв тяжелыми металлами, которые токсичны для всех живых организмов и вызывают тяжелые заболевания животных и человека. Одним из наиболее безопасных методов очистки загрязненных территорий является фиторемедиация. Главной задачей в фиторемедиации почв является поиск растений-гипераккумуляторов, которые способны накапливать большие концентрации тяжелых металлов. Для повышения фиторемедиационной эффективности подобных растений целесообразна их трансформация генами, кодирующими синтез металлсвязывающих пептидов. Амарант является широко распространенной культурой, который имеет высокий потенциал для использования в фиторемедиации, так как отличается быстрым ростом, устойчивостью к неблагоприятным условиям среды и способностью накапливать высокие концентрации тяжелых металлов, в частности Сd и Ni. Ранее были получены растения Amaranthus retroflexus, трансформированные искусственно синтезированным геном pph6, собранным из комплементарных блоков 5'ATGGAATGCGAATGTGAGTGCGAGTGCGAGTGCGAATGTGGCTAA3' and 5'TTAGAGACACTCTCGCACTCGCACTCGCAT3'. После сшивки данных блоков, последовательность была клонирована в вектор для трансформации растений рСаmbia 1301 под регуляцией 35S промотора вируса мозаики цветной капусты и в дальнейшем использована для получения трансгенных растений амаранта. Для трансформации использовали гипокотили и эпикотили проростков амаранта на 14 день после появления всходов. Для регенерации побегов в среду добавляли 2 мг/л БАП и 0,2 мг/л НУК.

Было выявлено, что продукт гена pph6 повышает устойчивость растений к тяжелым металлам. В среднем на $18 \%$

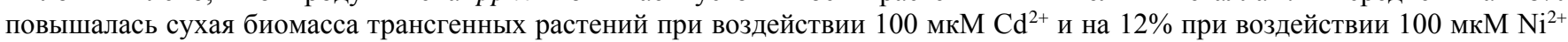
по сравнению с контрольными растениями. Содержание $\mathrm{Cd}^{2+}$ в трансгенных растениях было на $33 \%$ выше, чем в контрольных, в случае $\mathrm{Ni}^{2+}$ этот показатель повышался на $17 \%$. В целом $\mathrm{Ni}^{2+}$ оказался более токсичным для растений амаранта. Результаты экспериментов позволили сделать вывод о целесообразности использования pph6 для повышения фиторемедиационной эффективности растений.

Работа была выполнена при финансовой поддержке гранта Российского фонда фундаментальных исследований №18-3400033 мол_а. 